OPEN ACCESS

Edited by:

Junji Xing,

Houston Methodist Research Institute,

United States

Reviewed by:

Lubka T. Roumenina,

INSERM U1138 Centre de Recherche des Cordeliers (CRC), France

Yong Du,

Hospital for Special Surgery,

United States

*Correspondence:

Antonio Inforzato

antonio.inforzato@

humanitasresearch.it

Andrea Doni

andrea.doni@humanitasresearch.it

Specialty section: This article was submitted to

Molecular Innate Immunity,

a section of the journal

Frontiers in Immunology

Received: 29 September 2021 Accepted: 01 November 2021

Published: 18 November 2021

Citation:

Parente R, Possetti V, Erreni M, D'Autilia F, Bottazzi B, Garlanda C,

Mantovani $A$, Inforzato $A$ and

Doni A (2021) Complementary

Roles of Short and Long

Pentraxins in the ComplementMediated Immune Response to Aspergillus fumigatus Infections.

Front. Immunol. 12:785883. doi: 10.3389/fimmu.2021.785883

\section{Complementary Roles of Short and Long Pentraxins in the Complement- Mediated Immune Response to Aspergillus fumigatus Infections}

\author{
Raffaella Parente ${ }^{1}$, Valentina Possetti ${ }^{1}$, Marco Erreni ${ }^{1,2}$, Francesca D'Autilia ${ }^{1}$, \\ Barbara Bottazzi $^{1}$, Cecilia Garlanda ${ }^{1,2}$, Alberto Mantovani ${ }^{1,2,3}$, Antonio Inforzato ${ }^{1,2 *}$ \\ and Andrea Doni ${ }^{1 *}$ \\ ${ }^{1}$ Istituto di Ricovero e Cura a Carattere Scientifico (IRCCS) Humanitas Research Hospital, Milan, Italy, ${ }^{2}$ Department of \\ Biomedical Sciences, Humanitas University, Milan, Italy, ${ }^{3}$ The William Harvey Research Institute, Queen Mary University of \\ London, London, United Kingdom
}

The ubiquitous mold Aspergillus fumigatus is the major etiologic agent of invasive aspergillosis, a life-threatening infection amongst immune compromised individuals. An increasing body of evidence indicates that effective disposal of $A$. fumigatus requires the coordinate action of both cellular and humoral components of the innate immune system. Early recognition of the fungal pathogen, in particular, is mediated by a set of diverse soluble pattern recognition molecules (PRMs) that act as "ancestral antibodies" inasmuch as they are endowed with opsonic, pro-phagocytic and killing properties. Pivotal is, in this respect, the contribution of the complement system, which functionally cooperates with cell-borne pattern recognition receptors (PRRs) and other soluble PRMs, including pentraxins. Indeed, complement and pentraxins form an integrated system with crosstalk, synergism, and regulation, which stands as a paradigm of the interplay between PRMs in the mounting and orchestration of antifungal immunity. Following upon our past experience with the long pentraxin PTX3, a well-established immune effector in the host response to $A$. fumigatus, we recently reported that this fungal pathogen is targeted in vitro and in vivo by the short pentraxin Serum Amyloid $P$ component (SAP) too. Similar to PTX3, SAP promotes phagocytosis and disposal of the fungal pathogen via complement-dependent pathways. However, the two proteins exploit different mechanisms of complement activation and receptor-mediated phagocytosis, which further extends complexity and integration of the complementpentraxin crosstalk in the immune response to $A$. fumigatus. Here we revisit this crosstalk in light of the emerging roles of SAP as a novel PRM with antifungal activity.

Keywords: Aspergillus fumigatus, aspergillosis, innate immunity, pentraxins, complement 


\section{INTRODUCTION}

Aspergillosis is a collective name for Aspergillus species-related infections that clinically manifest as either non-invasive (i.e., allergic bronchopulmonary aspergillosis, ABPA, chronic pulmonary aspergillosis, CPA, and aspergilloma), or invasive diseases (1). Invasive aspergillosis (IA) is the most severe form, with 10 million individuals at risk, more than 200,000 deaths/ year worldwide, and a mortality rate of up to $90 \%$ in the worst scenarios (https://www.aspergillus.org.uk/). Several factors contribute to the risk and severity of IA, including microbial virulence, limited therapeutic pipeline and diagnostic inaccuracy, however it is the host's immune status that primarily determines onset and progression of IA, with immune-compromised individuals being the most vulnerable (2).

IA is mainly caused by Aspergillus fumigatus (AF), an obligate aerobic filamentous fungus that spreads in the environment in the form of quiescent airborne spores (dormant or resting conidia) (3). Up to a few hundred spores are inhaled by humans daily, and, in immune competent individuals, most of them are mechanically eliminated by the ciliated and mucus-secreting cells of the epithelial barrier of the upper airways (4). Those who skip mucociliary clearance are promptly recognized, phagocytosed and killed by alveolar epithelial cells (mostly, type II pneumocytes) and cellular effectors of the innate immune system, including resident alveolar macrophages (AMs) and dendritic cells (DCs) as well as recruited polymorphonuclear neutrophils (5). These cells are all endowed with an armamentarium of pattern recognition receptors (PRRs) that recognize a spectrum of pathogen associated molecular patterns (PAMPs) on fungal spores, and activate mechanisms of defence (6). Neutrophils are particularly important in this respect, indeed iatrogenic, acquired and inherited defects in number, function or homing of these cells are major risk factors for IA (7).

Recognition and disposal of fungal particles are also mediated by soluble effectors of innate immunity, including complement, an ancestral system of soluble and cell-borne pattern recognition molecules (PRMs) $(8,9)$. Other PRMs are known to functionally cooperate with complement in the handling of AF infections, including ficolins, collectins and pentraxins. In particular, the long pentraxin PTX3 is an established complement-dependent PRM with host protective functions against AF [reviewed in (10)]. We have recently reported that the classical short pentraxin serum amyloid $\mathrm{P}$ component (SAP) promotes recognition, phagocytosis and killing of AF. However, this occurs through different complement-dependent mechanisms (11), which highlights complexity and integration of the innate immune reaction to fungal pathogens. Here, we discuss the pentraxin-complement interplay in IA, with a major focus on the most recent evidence from in vitro studies, animal modeling, and human genetics.

\section{PENTRAXINS AND THEIR INTERACTION WITH THE COMPLEMENT SYSTEM}

Pentraxins are a superfamily of phylogenetically conserved proteins with regulatory functions in inflammation (12).
C-reactive protein (CRP) and SAP, prototypes of the short pentraxins arm of the family, opsonize microbial pathogens and apoptotic cells, thus acting as soluble PRMs towards pathogen and danger associated molecular patterns, and support their complement-mediated clearance (13). CRP comprises 5 non-glycosylated subunits (14), whereas SAP is a plasma glycoprotein with 5 or 10 protomers (15). Both proteins share a peculiar quaternary structure with homo-oligomers folding into pentameric rings stabilized by non-covalent interactions (16).

In addition to CRP and SAP, PTX3 is a typical long pentraxin, with a C-terminal domain homologous to the short pentraxins, and an N-terminal region with no similarity to other proteins. The human PTX3 is a $340 \mathrm{kDa}$ glycoprotein (17) made of 8 identical protomer subunits folding into a disulphide bondstabilized octamer $(18,19)$. The amino acid sequence of PTX3 is highly conserved across species, suggesting an evolutionary pressure to preserve its structure/function relationships (20).

Despite these structural similarities, CRP, SAP and PTX3 are different in terms of cellular producers and molecular inducers. CRP and SAP are mainly synthesized in the liver, in response to IL-6 (21). CRP, whose serum concentration increases as much as 1000 times (from baseline levels of $0.8-1 \mathrm{mg} / \mathrm{L}$ ) during acute responses, is the prototypic acute phase protein in humans and clinically used as a sensitive, though non-specific, systemic marker of infection and inflammation. The serum concentration of the murine protein however mildly increases (up to $\sim 17 \mathrm{mg} / \mathrm{L}$ from baseline levels of $5-9 \mathrm{mg} / \mathrm{L}$ ) upon LPS injection, which points to different mechanisms of gene regulation in the two species (22). CRP recognizes microbes and apoptotic cells by binding to phosphocoline (PC), and promotes phagocytosis of the opsonized materials through activation of the classical pathway (CP) of complement (21). In addition, CRP restrains complement hyperactivation by binding to factor $\mathrm{H}(\mathrm{fH})$, major inhibitor of the alternative pathway (AP) (23). SAP is an acute phase protein in mouse [with serum concentrations of $\sim 500 \mu \mathrm{g} / \mathrm{L}$ and $\sim 20 \mathrm{mg} / \mathrm{L}$ in homeostatic and inflammatory conditions, respectively (11)], whereas it is constitutively present in the human plasma $(30-50 \mathrm{mg} / \mathrm{L}$ ), where it contributes to host defence via direct or indirect (complement-dependent) opsonic mechanisms (24). Similar to CRP, SAP binds C1q (recognition unit of the $\mathrm{CP}$ ) and promotes complement activation (25). While unable to bind $\mathrm{fH}$, SAP interacts with C4b-binding protein $(\mathrm{C} 4 \mathrm{BP})(25,26)$, major inhibitor of the CP pathway, indicating that, like CRP, SAP has complement regulating properties (27).

As opposed to CRP and SAP, PTX3 is rapidly synthesized and secreted at sites of infection/inflammation by a variety of immune and non-immune cells in response to TLR engagement, microbial moieties, and inflammatory cytokines (28-30). Mature neutrophils do not transcribe the PTX3 gene, however they store the pre-made protein in specific granules, and promptly release it upon degranulation (31). Similar to CRP and SAP, PTX3 binds C1q, and controls activation of the CP $(17,32)$. In addition, PTX3 interacts with components of the lectin pathway (LP), including mannose-binding lectin (MBL) (33), 
ficolin-1 (34) and -2 (35), and promotes LP deposition on AF and Candida albicans. Also, in an analogy with CRP and SAP, PTX3 controls excessive complement activation through specific interactions with $\mathrm{fH}$ (36) and C4BP (37) (see Figure 1 for an overview of pentraxins).

\section{PTX3 IN AF INFECTIONS}

The long pentraxin PTX3 is a PRM with established roles in the innate immune response to selected pathogens, and prognostic/ diagnostic potential as biochemical and genetic biomarker in many systemic infections (38), including invasive pulmonary aspergillosis (IPA) (39), and, more recently, COVID-19 (40). Initial evidence of the involvement of PTX3 in the host resistance to $\mathrm{AF}$ dates back to 2002, when it was reported that genetic deficiency of Ptx 3 enhances susceptibility to IPA in immunocompetent mice, due to defective recognition of fungal conidia by neutrophils, AMs, and DCs, and biased Th2 responses
(41). This phenotype was reverted by administration of the recombinant protein, and a close functional cooperation was established between PTX3, neutrophils, and the complement system $(31,42)$. These findings have been recapitulated and extended in experimental models of iatrogenic immune suppression (43) and primary immune deficiencies (44), clinical conditions that predispose to IPA. Furthermore, PTX3 polymorphisms have been associated to reduced systemic levels of the protein and increased risk of IPA in recipients of hematopoietic stem-cell (HSC) $(39,45)$ and solid organ transplants (46), chronic obstructive pulmonary disease patients (47) and individuals with hematological malignancies (48). Interestingly, this association is lost in conditions of severe neutropenia (49), which further supports the functional link with neutrophils originally foreseen in the mouse (41).

The mechanisms underlying the antifungal properties of PTX3 have been addressed in a study by Moalli et al., where this pentraxin was shown to opsonize AF conidia and promote their phagocytosis and killing by human (in vitro) and mouse

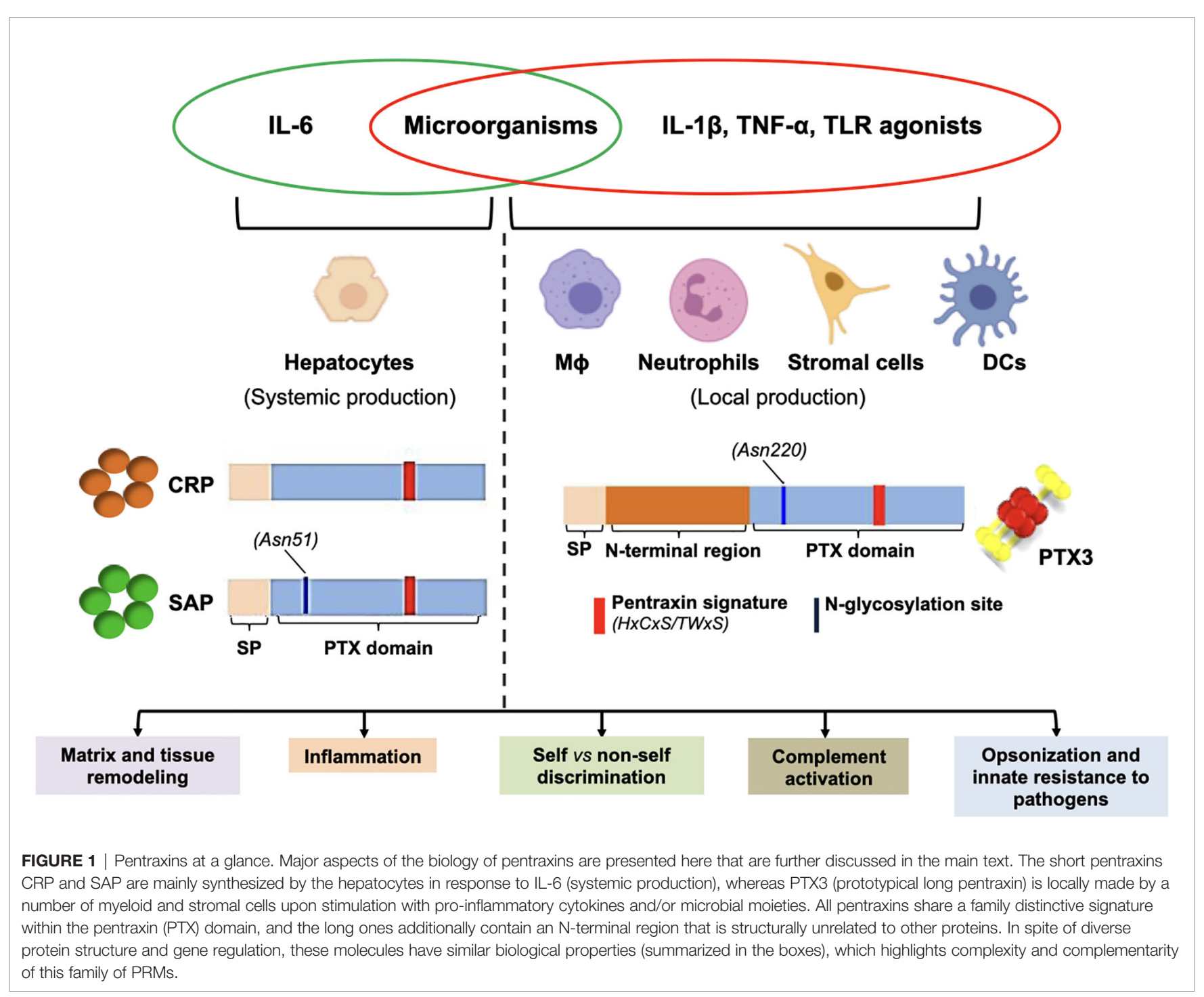


(in vivo) neutrophils via AP, complement receptor 3 (CR3), and $\mathrm{Fc} \gamma$ receptors (Fc $\gamma \mathrm{Rs}$ ) pathways (42). This and previous investigations (41) ruled out contributions of $\mathrm{CP}(\mathrm{C} 1 \mathrm{q}$ in particular) to the pro-phagocytic activity of PTX3. Also, ficolin-2 and PTX3 have been reported to recruit each other to the wall of AF conidia, and promote synergic amplification of the $\mathrm{LP}$, however this mechanism is relevant in conditions of $\mathrm{C} 1 \mathrm{q}$ and MBL deficiency only (35). Therefore, available evidence indicates that a functionally competent AP is required for the prophagocytic and pro-killing activities of PTX3 in AF infections [see Figure 2A and (10) for a more comprehensive review of the interplay between PTX3 and complement in these diseases].

\section{SAP AND MICROBIAL PATHOGENS}

SAP is recognized as a component of the innate immune response to microbial pathogens, including Gram-positive (50, 51) and Gram-negative bacteria (52) and viruses (53), and traditionally described as an opsonin that acts through Fc $\gamma$ Rs and complement mechanisms (54-58). However, the actual role of SAP in clinical infections is unclear (52), likely due to divergent gene regulation in mice and humans (16, 21, 59), and conflicting evidence from in vitro and in vivo settings (52). For example, SAP interacts with spikes on the viral envelope of the influenza A virus, inhibits hemagglutination, and neutralizes virus infectivity in vitro $(53,60)$, however it has no clear role in human influenza (61). Also, in spite of inhibitory effects on the intra-erythrocytic growth of malaria parasites (62) and uptake of Mycobacterium tuberculosis by murine AMs in vitro (63), no data are available to support a role of SAP in malaria and tuberculosis in vivo. Furthermore, a clear correlation between microbial recognition, opsonic activity and microbicidal function of this pentraxin is missing. In this regard, SAP is known to interact with Streptococcus pneumoniae and promote its phagocytosis in vitro and in vivo (51), however it enhances the macrophagedependent killing of Listeria monocytogenes, a pathogen it does not bind (64). Also, this short pentraxin recognizes Mycobacterium tuberculosis, and inhibits recognition and killing of this pathogen by macrophages (63). On the same line, its interaction with Streptococcus pyogenes, Neisseria meningitides, and some strains of Escherichia coli results into decreased phagocytosis and killing by macrophages and inhibition of complement, and SAP-deficient mice have increased survival in experimental infections with Streptococcus pyogenes or Escherichia coli (52). Based on these and other

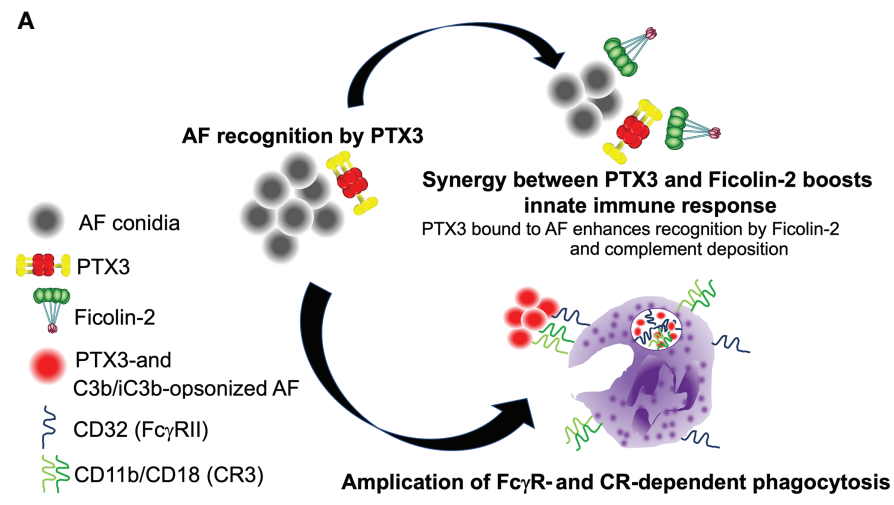

B

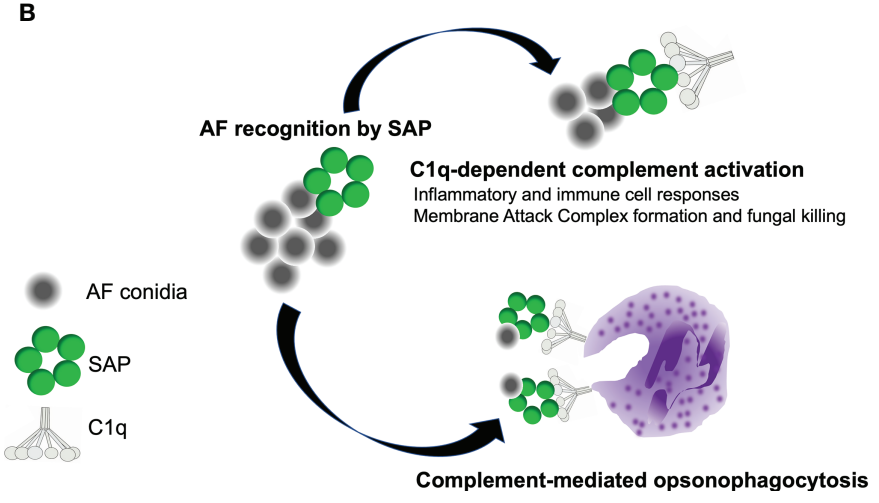

FIGURE 2 | Complement-dependent roles of PTX3 and SAP in the host resistance to A. fumigatus. (A) PTX3 and Ficolin-2 recruit each other onto AF conidia, and activate the LP. As C3b and iC3b deposit (via the AP amplification loop), PTX3 promotes phagocytosis of AF via FcyRII (CD32)-dependent redistribution of CD11b (that forms with CD18 the complement receptor 3, CR3, major receptor of iC3b) to the phagocytic cup. (B) SAP recruits C1q to AF conidia, and promotes CP activation. This leads to enhanced disposal of the pathogen through neutrophil-dependent phagocytosis and MAC-mediated killing. 
evidence, the opsonic nature of SAP has been questioned (52), and pharmacological depletion rather than administration of SAP has been proposed to treat invasive infections (65). Moreover, the regulatory mechanisms through which SAP participates in the immune response to unligated microbial pathogens are yet to be defined.

\section{EMERGING ROLES OF SAP IN ANTIFUNGAL IMMUNITY}

A functional interaction of SAP with filamentous forms of pathogenic fungi has been proposed (66), based on histology of autoptic specimens from patients with invasive gastrointestinal candidiasis, aspergillosis, mucormycosis, and coccidioidomycosis $(67,68)$. Also, in a mouse model of chronic AF-induced allergic asthma, administration of SAP inhibited alternative macrophage activation, airway remodeling and inflammation (69). This occurred via engagement of Fc $\gamma$ Rs (70), a mechanism through which SAP controls fibrocyte differentiation in addition to alternative macrophage polarization $(71,72)$.

SAP is a well-known player in amyloidosis, where it binds and stabilizes amyloid fibrils (73). These form on the surface of invading yeasts and fungi too (68), which suggests that SAP might contribute to the pathogenicity of these microbes by stabilizing amyloid deposits that interfere with immune recognition (67). Indeed, the interaction of SAP with amyloid fibrils on Candida albicans inhibits phagocytosis and cytokine production in macrophages (74). However, genetic deficiency of SAP had no effect in a mouse model of candidiasis (11).

We have recently reported that SAP is an essential element of the host resistance to AF and other clinically relevant fungi of the Trichocomaceae family, including A. flavus and A. terreus (11). In a murine model of lung aspergillosis, SAP interacts with AF conidia, and triggers complement-mediated inflammatory responses that are essential for pathogen removal. Indeed, SAP-deficient mice are more susceptible to the experimental infection, due to reduced recruitment and phagocytic activity of neutrophils, and resistance to AF is rescued in these animals by administration of the recombinant murine protein. Also, the recombinant human protein, currently under evaluation for therapy of idiopathic pulmonary fibrosis (IPF) (75-77), has therapeutic efficacy against AF in transiently myelosuppressed mice, an experimental setting that closely mimics iatrogenic IA in humans. More importantly, polymorphisms in the APCS gene (coding for the SAP protein) are associated to the risk of IPA (11).

We have shown that SAP binding to AF conidia results into deposition of $\mathrm{C} 3$ and production of the anaphylatoxin C5a, which is required for effective recruitment and phagocytic activity of neutrophils in the infected lung (78). Consistent with this, the plasma of $A p c s^{-/-}$mice had decreased C3 activation and $\mathrm{C} 5 \mathrm{a}$ levels when challenged with AF conidia in vitro, and pre-opsonization with the murine protein rescued complement activation and AF phagocytosis by neutrophils from SAP-deficient and -competent mice. Also, in the presence of active complement, bone marrow-derived macrophages from $A p c s^{-/-}$animals had reduced production of cytokines when exposed to AF conidia, further strengthening the point that SAP exerts a complement-dependent pro-inflammatory role in IA (11). Based on opsono-phagocytosis experiments with human and mouse sera depleted of selected complement components, we demonstrated that, when opsonized to AF, SAP promotes activation of the $\mathrm{CP}$, a major initiator of complement in $\mathrm{AF}$ infections (79) (Figure 2B). As opposed to this, the prophagocytic activity of PTX3 does not require $\mathrm{C1q}$ (and the CP) $(41,42)$, likely due to the conidia-bound protein being unable to bind $\mathrm{Clq}$ and/or induce the structural rearrangements that are needed for this protein to activate the CP (80). Moreover, SAPmediated induction of complement culminates in the formation on AF conidia of the membrane attack complex (MAC; C5b-C9), and fungal killing, pointing to a complement-dependent microbicidal effect of this pentraxin in the serum (11).

Adaptive immunity plays an important role in fungal infections, whereby anti-AF IgG seroprevalence has been described in geographic areas with prevalence of chronic pulmonary aspergillosis, and anti-AF IgGs have been detected in healthy subjects too (81). Also, neutrophils, major cellular players in IPA, express Fc $\gamma$ Rs (78), and SAP has been proposed as a ligand of Fc $\gamma$ Rs (70). Using antibodies to block Fc $\gamma$ Rs or IgGdepleted plasma, we have indeed documented decreased phagocytosis of AF by neutrophils, suggesting that the IgG/ $\mathrm{Fc} \gamma \mathrm{R}$ axis is involved in fungal removal by these cells (11). However, SAP retained its pro-phagocytic activity on neutrophils even in conditions of Fc $\gamma$ Rs blockade or IgG depletion, indicating that the antibody-mediated engagement of FcyRs is dispensable for the SAP-dependent opsonophagocytosis of AF. Interestingly, pre-opsonization of conidia with SAP potentiated C3 deposition even in IgG-depleted plasma, a condition that mimics antibody deficiencies in humans. Also, SAP amplified phagocytosis of AF by monocytes and macrophages, in addition to neutrophils, but failed to do so with DCs, possibly due to these cells expressing low levels of complement receptors (82).

We have reported that single nucleotide polymorphisms in the APCS gene of HSC donors (rs2808661 and rs3753869 SNPs) are associated with the incidence of IPA in recipients of allogeneic HSC transplants (11). Homozygous for the pathological alleles are relatively rare in the general population, however, these genotypes have a high degree of penetrance with cumulative incidence of infection of $\sim 50 \%$. This suggests that SAP is of pathogenetic relevance in human IPA, and indicates that genetic variation in the APCS gene might be clinically valuable, for example, to screen donors in HSC transplantation and identify individuals at high risk of IPA. The genetic association between SAP and IPA is quite surprising, given that the expression of this pentraxin is traditionally confined to the liver (72). However, local expression of SAP has been documented in atherosclerotic (83) and fibrotic lesions (84), and, more importantly, in silico analyses have detected APCS mRNA in human and murine immune cells (including neutrophils, monocytes and macrophages) in inflammatory 
conditions. Also, APCS is expressed in peripheral monocytes from COVID-19 patients (11). Interestingly, the concentration of SAP increases in the BALF but not in the blood of IPA patients, and lower levels of the protein have been found in the serum of recipients of HSC from donors with the IPA-associated APCS genotypes (11), suggesting that SAP is a local rather than systemic player in IPA pathogenesis.

CRP has been reported to increase in the serum of IA patients $(85,86)$, recognize fractions of the AF hyphal wall (87), and promote AF phagocytosis by human neutrophils in vitro (88). However, whether this short pentraxin is involved in the pathogenesis of IA in vivo is unknown.

\section{DISCUSSION}

Experimental and clinical evidence indicates that the long pentraxin PTX3 and the short pentraxin SAP are key players in the host resistance to fungal infections, particularly those mediated by $A$. fumigatus. These proteins both exert complement-dependent pro-phagocytic and pro-killing activities, and closely crosstalk to major cellular components of the innate immune system, especially neutrophils. Interestingly, they cooperate with distinct pathways of complement, and exhibit diverse FcyRs requirements $(11,42)$, which points to integrated and, possibly, complementary roles of the two pentraxins in antifungal immunity. In this regard, PTX3 has been shown to add on or synergizes with clinically established antifungal drugs in several animal models of IPA (43, 89-91). Whether this is the case for SAP too remains to be assessed, however, based on our current mechanistic understanding, it is envisaged that the combination of the two proteins might have additive or synergic effects, and possibly pave the way to new therapeutic options against drug-resistant AF strains (92).

In our model of AF infection in immunosuppressed mice the recombinant human SAP had therapeutic efficacy at comparable doses to those used in lung fibrosis (84) and influenza (93), which fosters translation to prophylaxis and therapy of IPA in immunecompromised patients (94). Also, given the fact that SAP mediates assembly of MAC on AF and fungal killing in the serum, this pentraxin might find therapeutic applications in conditions of neutropenia too. The interaction of SAP with

\section{REFERENCES}

1. Agarwal R, Chakrabarti A. Allergic Bronchopulmonary Aspergillosis in Asthma: Epidemiological, Clinical and Therapeutic Issues. Future Microbiol (2013) 8(11):1463-74. doi: 10.2217/fmb.13.116

2. Brown GD, Denning DW, Gow NA, Levitz SM, Netea MG, White TC. Hidden Killers: Human Fungal Infections. Sci Transl Med (2012) 4 (165):165rv13. doi: 10.1126/scitranslmed.3004404

3. Dagenais TR, Keller NP. Pathogenesis of Aspergillus Fumigatus in Invasive Aspergillosis. Clin Microbiol Rev (2009) 22(3):447-65. doi: 10.1128/ CMR.00055-08

4. Croft CA, Culibrk L, Moore MM, Tebbutt SJ. Interactions of Aspergillus Fumigatus Conidia With Airway Epithelial Cells: A Critical Review. Front Microbiol (2016) 7:472. doi: 10.3389/fmicb.2016.00472
Fc $\gamma R$ s is known to inhibit the alternative activation of macrophages (69), which restrains tissue fibrosis in vivo (71, 84 ). Based on this rationale, SAP has been shown to have antifibrotic activity in mouse models of chronic diseases of the kidney (95) and lung (84), and in the prophylactic treatment of influenza (93). More importantly, a recombinant form of human SAP (PRM-151) has been proposed as a novel antifibrotic immunomodulator in IPF patients, based on phase 2 randomized and placebo-controlled trials, with no serious adverse reactions (75-77), which encourages clinical trials to evaluate the efficacy of this short pentraxin, in addition to PTX3, in the treatment of IA. In an era of COVID-19 pandemic, these translational efforts are timely, given that a strong and independent association has been established between IPA and the COVID-19 disease $(96,97)$.

\section{AUTHOR CONTRIBUTIONS}

RP wrote the "PTX3 in AF infections" chapter. VP wrote the "Introduction" chapter. ME wrote the "Pentraxins and their interaction with the complement system" chapter. AD wrote the "SAP and microbial pathogens" and "Emerging roles of SAP in antifungal immunity" chapters. FD, RP, and VP generated the figures. AI conceptualized and outlined the manuscript, wrote the Abstract and the "Discussion" chapter, and revised the manuscript. $\mathrm{BB}, \mathrm{CG}, \mathrm{AM}$, and $\mathrm{AD}$ contributed to critical revision of the manuscript. All authors contributed to the article and approved the submitted version.

\section{FUNDING}

The authors gratefully acknowledge Fondazione Beppe e Nuccy Angiolini for funding a post-doctoral fellowship (recipient RP) and a technician contract (recipient VP). Most of the work done on PTX3 and SAP in the last years has been funded by the European Commission (ERC project PHII-669415 to AM) and the Italian Ministry of Health (GR-2011-02349539 to AI). We are also grateful to Associazione Italiana Ricerca sul Cancro (AIRC, IG-21714 to CG, and IG-23465 to AM) for the financial support.

5. Latge JP, Chamilos G. Aspergillus Fumigatus and Aspergillosis in 2019. Clin Microbiol Rev (2019) 33(1). doi: 10.1128/CMR.00140-18

6. Erwig LP, Gow NA. Interactions of Fungal Pathogens With Phagocytes. Nat Rev Microbiol (2016) 14(3):163-76. doi: 10.1038/nrmicro.2015.21

7. Gazendam RP, van Hamme JL, Tool AT, Hoogenboezem M, van den Berg JM, Prins JM, et al. Human Neutrophils Use Different Mechanisms To Kill Aspergillus Fumigatus Conidia and Hyphae: Evidence From Phagocyte Defects. J Immunol (2016) 196(3):1272-83. doi: 10.4049/jimmunol.1501811

8. Merle NS, Church SE, Fremeaux-Bacchi V, Roumenina LT. Complement System Part I - Molecular Mechanisms of Activation and Regulation. Front Immunol (2015) 6:262. doi: 10.3389/fimmu.2015.00262

9. Merle NS, Noe R, Halbwachs-Mecarelli L, Fremeaux-Bacchi V, Roumenina LT. Complement System Part II: Role in Immunity. Front Immunol (2015) 6:257. doi: 10.3389/fimmu.2015.00257 
10. Parente R, Doni A, Bottazzi B, Garlanda C, Inforzato A. The Complement System in Aspergillus Fumigatus Infections and Its Crosstalk With Pentraxins. FEBS Lett (2020) 594(16):2480-501. doi: 10.1002/1873-3468.13744

11. Doni A, Parente R, Laface I, Magrini E, Cunha C, Colombo FS, et al. Serum Amyloid P Component Is an Essential Element of Resistance Against Aspergillus Fumigatus. Nat Commun (2021) 12(1):3739. doi: 10.1038/ s41467-021-24021-y

12. Doni A, Stravalaci M, Inforzato A, Magrini E, Mantovani A, Garlanda C, et al. The Long Pentraxin PTX3 as a Link Between Innate Immunity, Tissue Remodeling, and Cancer. Front Immunol (2019) 10:712. doi: 10.3389/ fimmu.2019.00712

13. Poon IK, Hulett MD, Parish CR. Molecular Mechanisms of Late Apoptotic/ Necrotic Cell Clearance. Cell Death Differ (2010) 17(3):381-97. doi: 10.1038/ cdd.2009.195

14. Shrive AK, Cheetham GM, Holden D, Myles DA, Turnell WG, Volanakis JE, et al. Three Dimensional Structure of Human C-Reactive Protein. Nat Struct Biol (1996) 3(4):346-54. doi: 10.1038/nsb0496-346

15. Emsley J, White HE, O'Hara BP, Oliva G, Srinivasan N, Tickle IJ, et al. Structure of Pentameric Human Serum Amyloid P Component. Nature (1994) 367(6461):338-45. doi: 10.1038/367338a0

16. Bottazzi B, Inforzato A, Messa M, Barbagallo M, Magrini E, Garlanda C, et al. The Pentraxins PTX3 and SAP in Innate Immunity, Regulation of Inflammation and Tissue Remodelling. J Hepatol (2016) 64(6):1416-27. doi: 10.1016/j.jhep.2016.02.029

17. Inforzato A, Peri G, Doni A, Garlanda C, Mantovani A, Bastone A, et al. Structure and Function of the Long Pentraxin PTX3 Glycosidic Moiety: FineTuning of the Interaction With $\mathrm{C} 1 \mathrm{q}$ and Complement Activation. Biochemistry (2006) 45(38):11540-51. doi: 10.1021/bi0607453

18. Inforzato A, Rivieccio V, Morreale AP, Bastone A, Salustri A, Scarchilli L, et al. Structural Characterization of PTX3 Disulfide Bond Network and Its Multimeric Status in Cumulus Matrix Organization. J Biol Chem (2008) 283 (15):10147-61. doi: 10.1074/jbc.M708535200

19. Inforzato A, Baldock C, Jowitt TA, Holmes DF, Lindstedt R, Marcellini M, et al. The Angiogenic Inhibitor Long Pentraxin PTX3 Forms an Asymmetric Octamer With Two Binding Sites for FGF2. J Biol Chem (2010) 285 (23):17681-92. doi: 10.1074/jbc.M109.085639

20. Garlanda C, Bottazzi B, Magrini E, Inforzato A, Mantovani A. Ptx3, a Humoral Pattern Recognition Molecule, in Innate Immunity, Tissue Repair, and Cancer. Physiol Rev (2018) 98(2):623-39. doi: 10.1152/physrev. 00016.2017

21. Pepys MB, Hirschfield GM. C-Reactive Protein: A Critical Update. J Clin Invest (2003) 111(12):1805-12. doi: 10.1172/JCI200318921

22. Sproston NR, Ashworth JJ. Role of C-Reactive Protein at Sites of Inflammation and Infection. Front Immunol (2018) 9:754. doi: 10.3389/ fimmu.2018.00754

23. Jarva H, Jokiranta TS, Hellwage J, Zipfel PF, Meri S. Regulation of Complement Activation by C-Reactive Protein: Targeting the Complement Inhibitory Activity of Factor $\mathrm{H}$ by an Interaction With Short Consensus Repeat Domains 7 and 8-11. J Immunol (1999) 163(7):3957-62.

24. Bijl M, Bootsma H, van der Geld Y, Limburg PC, Kallenberg CG, Van Rijswijk MH. Serum Amyloid P Component Levels Are Not Decreased in Patients With Systemic Lupus Erythematosus and Do Not Rise During an Acute Phase Reaction. Ann Rheum Dis (2004) 63(7):831-5. doi: 10.1136/ard.2002.004796

25. Sorensen IJ, Nielsen EH, Andersen O, Danielsen B, Svehag SE. Binding of Complement Proteins C1q and C4bp to Serum Amyloid P Component (SAP) in Solid Contra Liquid Phase. Scand J Immunol (1996) 44(4):401-7. doi: 10.1046/j.1365-3083.1996.d01-326.x

26. Garcia de Frutos P, Hardig Y, Dahlback B. Serum Amyloid P Component Binding to C4b-Binding Protein. J Biol Chem (1995) 270(45):26950-5. doi: $10.1074 /$ jbc. 270.45 .26950

27. Haapasalo K, Meri S. Regulation of the Complement System by Pentraxins. Front Immunol (2019) 10:1750. doi: 10.3389/fimmu.2019.01750

28. Daigo K, Inforzato A, Barajon I, Garlanda C, Bottazzi B, Meri S, et al. Pentraxins in the Activation and Regulation of Innate Immunity. Immunol Rev (2016) 274(1):202-17. doi: 10.1111/imr.12476

29. Erreni M, Manfredi AA, Garlanda C, Mantovani A, Rovere-Querini P. The Long Pentraxin PTX3: A Prototypical Sensor of Tissue Injury and a Regulator of Homeostasis. Immunol Rev (2017) 280(1):112-25. doi: 10.1111/imr.12570
30. Doni A, D'Amico G, Morone D, Mantovani A, Garlanda C. Humoral Innate Immunity at the Crossroad Between Microbe and Matrix Recognition: The Role of PTX3 in Tissue Damage. Semin Cell Dev Biol (2017) 61:31-40. doi: 10.1016/j.semcdb.2016.07.026

31. Jaillon S, Peri G, Delneste Y, Fremaux I, Doni A, Moalli F, et al. The Humoral Pattern Recognition Receptor PTX3 Is Stored in Neutrophil Granules and Localizes in Extracellular Traps. J Exp Med (2007) 204(4):793-804. doi: 10.1084/jem.20061301

32. Nauta AJ, Bottazzi B, Mantovani A, Salvatori G, Kishore U, Schwaeble WJ, et al. Biochemical and Functional Characterization of the Interaction Between Pentraxin 3 and C1q. Eur J Immunol (2003) 33(2):465-73. doi: 10.1002/ immu. 200310022

33. Ma YJ, Doni A, Skjoedt MO, Honore C, Arendrup M, Mantovani A, et al. Heterocomplexes of Mannose-Binding Lectin and the Pentraxins PTX3 or Serum Amyloid P Component Trigger Cross-Activation of the Complement System. J Biol Chem (2011) 286(5):3405-17. doi: 10.1074/jbc.M110.190637

34. Ma YJ, Doni A, Romani L, Jurgensen HJ, Behrendt N, Mantovani A, et al. Ficolin-1-PTX3 Complex Formation Promotes Clearance of Altered Self-Cells and Modulates IL-8 Production. J Immunol (2013) 191(3):1324-33. doi: 10.4049/jimmunol.1300382

35. Ma YJ, Doni A, Hummelshoj T, Honore C, Bastone A, Mantovani A, et al. Synergy Between Ficolin-2 and Pentraxin 3 Boosts Innate Immune Recognition and Complement Deposition. J Biol Chem (2009) 284 (41):28263-75. doi: 10.1074/jbc.M109.009225

36. Deban L, Jarva H, Lehtinen MJ, Bottazzi B, Bastone A, Doni A, et al. Binding of the Long Pentraxin PTX3 to Factor H: Interacting Domains and Function in the Regulation of Complement Activation. J Immunol (2008) 181 (12):8433-40. doi: 10.4049/jimmunol.181.12.8433

37. Braunschweig A, Jozsi M. Human Pentraxin 3 Binds to the Complement Regulator C4b-Binding Protein. PloS One (2011) 6(8):e23991. doi: 10.1371/ journal.pone.0023991

38. Porte R, Davoudian S, Asgari F, Parente R, Mantovani A, Garlanda C, et al. The Long Pentraxin PTX3 as a Humoral Innate Immunity Functional Player and Biomarker of Infections and Sepsis. Front Immunol (2019) 10:794. doi: 10.3389/fimmu.2019.00794

39. Cunha C, Aversa F, Lacerda JF, Busca A, Kurzai O, Grube M, et al. Genetic PTX3 Deficiency and Aspergillosis in Stem-Cell Transplantation. N Engl J Med (2014) 370(5):421-32. doi: 10.1056/NEJMoa1211161

40. Brunetta E, Folci M, Bottazzi B, De Santis M, Gritti G, Protti A, et al. Macrophage Expression and Prognostic Significance of the Long Pentraxin PTX3 in COVID-19. Nat Immunol (2021) 22(1):19-24. doi: 10.1038/s41590020-00832-x

41. Garlanda C, Hirsch E, Bozza S, Salustri A, De Acetis M, Nota R, et al. NonRedundant Role of the Long Pentraxin PTX3 in Anti-Fungal Innate Immune Response. Nature (2002) 420(6912):182-6. doi: 10.1038/nature01195

42. Moalli F, Doni A, Deban L, Zelante T, Zagarella S, Bottazzi B, et al. Role of Complement and Fc\{gamma\} Receptors in the Protective Activity of the Long Pentraxin PTX3 Against Aspergillus Fumigatus. Blood (2010) 116(24):517080. doi: 10.1182/blood-2009-12-258376

43. Lo Giudice P, Campo S, Verdoliva A, Rivieccio V, Borsini F, De Santis R, et al. Efficacy of PTX3 in a Rat Model of Invasive Aspergillosis. Antimicrob Agents Chemother (2010) 54(10):4513-5. doi: 10.1128/AAC.00674-10

44. D'Angelo C, De Luca A, Zelante T, Bonifazi P, Moretti S, Giovannini G, et al. Exogenous Pentraxin 3 Restores Antifungal Resistance and Restrains Inflammation in Murine Chronic Granulomatous Disease. J Immunol (2009) 183(7):4609-18. doi: 10.4049/jimmunol.0900345

45. Fisher CE, Hohl TM, Fan W, Storer BE, Levine DM, Zhao LP, et al. Validation of Single Nucleotide Polymorphisms in Invasive Aspergillosis Following Hematopoietic Cell Transplantation. Blood (2017) 129(19):2693-701. doi: 10.1182/blood-2016-10-743294

46. Wojtowicz A, Lecompte TD, Bibert S, Manuel O, Rueger S, Berger C, et al. PTX3 Polymorphisms and Invasive Mold Infections After Solid Organ Transplant. Clin Infect Dis (2015) 61(4):619-22. doi: 10.1093/cid/civ386

47. He Q, Li H, Rui Y, Liu L, He B, Shi Y, et al. Pentraxin 3 Gene Polymorphisms and Pulmonary Aspergillosis in Chronic Obstructive Pulmonary Disease Patients. Clin Infect Dis (2018) 66(2):261-7. doi: 10.1093/cid/cix749

48. Herrero-Sanchez MC, Angomas EB, de Ramon C, Telleria JJ, Corchete LA, Alonso S, et al. Polymorphisms in Receptors Involved in Opsonic and 
Nonopsonic Phagocytosis, and Correlation With Risk of Infection in Oncohematology Patients. Infect Immun (2018) 86(12). doi: 10.1128/ IAI.00709-18

49. Brunel AS, Wojtowicz A, Lamoth F, Spertini O, Neofytos D, Calandra T, et al. Pentraxin-3 Polymorphisms and Invasive Mold Infections in Acute Leukemia Patients With Intensive Chemotherapy. Haematologica (2018) 103(11): e527e530. doi: 10.3324/haematol.2018.195453

50. An JH, Kurokawa K, Jung DJ, Kim MJ, Kim CH, Fujimoto Y, et al. Human SAP Is a Novel Peptidoglycan Recognition Protein That Induces Complement-Independent Phagocytosis of Staphylococcus Aureus. J Immunol (2013) 191(6):3319-27. doi: 10.4049/jimmunol.1300940

51. Yuste J, Botto M, Bottoms SE, Brown JS. Serum Amyloid P Aids ComplementMediated Immunity to Streptococcus Pneumoniae. PloS Pathog (2007) 3 (9):1208-19. doi: 10.1371/journal.ppat.0030120

52. Noursadeghi M, Bickerstaff MC, Gallimore JR, Herbert J, Cohen J, Pepys MB. Role of Serum Amyloid P Component in Bacterial Infection: Protection of the Host or Protection of the Pathogen. Proc Natl Acad Sci USA (2000) 97 (26):14584-9. doi: 10.1073/pnas.97.26.14584

53. Andersen O, Vilsgaard Ravn K, Juul Sorensen I, Jonson G, Holm Nielsen E, Svehag SE. Serum Amyloid P Component Binds to Influenza A Virus Haemagglutinin and Inhibits the Virus Infection In Vitro. Scand J Immunol (1997) 46(4):331-7. doi: 10.1046/j.1365-3083.1997.d01-147.x

54. Schwalbe RA, Dahlback B, Coe JE, Nelsestuen GL. Pentraxin Family of Proteins Interact Specifically With Phosphorylcholine and/or Phosphorylethanolamine. Biochemistry (1992) 31(20):4907-15. doi: 10.1021/ bi00135a023

55. Hind CR, Collins PM, Baltz ML, Pepys MB. Human Serum Amyloid P Component, a Circulating Lectin With Specificity for the Cyclic 4,6-Pyruvate Acetal of Galactose. Interact Various Bacteria Biochem J (1985) 225(1):10711. doi: $10.1042 /$ bj2250107

56. Du Clos TW, Mold C. Pentraxins (CRP, SAP) in the Process of Complement Activation and Clearance of Apoptotic Bodies Through Fcgamma Receptors. Curr Opin Organ Transplant (2011) 16(1):15-20. doi: 10.1097/MOT. 0b013e32834253c7

57. Ma YJ, Lee BL, Garred P. An Overview of the Synergy and Crosstalk Between Pentraxins and Collectins/Ficolins: Their Functional Relevance in Complement Activation. Exp Mol Med (2017) 49(4):e320. doi: 10.1038/ emm.2017.51

58. Doni A, Garlanda C, Bottazzi B, Meri S, Garred P, Mantovani A. Interactions of the Humoral Pattern Recognition Molecule PTX3 With the Complement System. Immunobiology (2012) 217(11):1122-8. doi: 10.1016/j.imbio.2012.07.004

59. Mantovani A, Garlanda C, Doni A, Bottazzi B. Pentraxins in Innate Immunity: From C-Reactive Protein to the Long Pentraxin PTX3. J Clin Immunol (2008) 28(1):1-13. doi: 10.1007/s10875-007-9126-7

60. Job ER, Bottazzi B, Gilbertson B, Edenborough KM, Brown LE, Mantovani A, et al. Serum Amyloid P Is a Sialylated Glycoprotein Inhibitor of Influenza A Viruses. PloS One (2013) 8(3):e59623. doi: 10.1371/journal.pone.0059623

61. Herbert J, Hutchinson WL, Carr J, Ives J, Jakob-Roetne R, Yamamura K, et al. Influenza Virus Infection Is Not Affected by Serum Amyloid P Component. Mol Med (2002) 8(1):9-15. doi: 10.1007/BF03401998

62. Balmer P, McMonagle F, Alexander J, Stephen Phillips R. Experimental Erythrocytic Malaria Infection Induces Elevated Serum Amyloid P Production in Mice. Immunol Lett (2000) 72(3):147-52. doi: 10.1016/S01652478(00)00180-2

63. Kaur S, Singh PP. Serum Amyloid P-Component-Mediated Inhibition of the Uptake of Mycobacterium Tuberculosis by Macrophages, In Vitro. Scand J Immunol (2004) 59(5):425-31. doi: 10.1111/j.0300-9475.2004.01412.x

64. Singh PP, Gervais F, Skamene E, Mortensen RF. Serum Amyloid PComponent-Induced Enhancement of Macrophage Listericidal Activity. Infect Immun (1986) 52(3):688-94. doi: 10.1128/iai.52.3.688-694.1986

65. Pepys MB. Invasive Candidiasis: New Insights Presaging New Therapeutic Approaches? J Infect Dis (2012) 206(9):1339-41. doi: 10.1093/infdis/jis521

66. Klotz SA, Sobonya RE, Lipke PN, Garcia-Sherman MC. Serum Amyloid P Component and Systemic Fungal Infection: Does It Protect the Host or Is It a Trojan Horse? Open Forum Infect Dis (2016) 3(3):ofw166. doi: 10.1093/ofid/ ofw166

67. Gilchrist KB, Garcia MC, Sobonya R, Lipke PN, Klotz SA. New Features of Invasive Candidiasis in Humans: Amyloid Formation by Fungi and
Deposition of Serum Amyloid P Component by the Host. J Infect Dis (2012) 206(9):1473-8. doi: 10.1093/infdis/jis464

68. Garcia-Sherman MC, Lundberg T, Sobonya RE, Lipke PN, Klotz SA. A Unique Biofilm in Human Deep Mycoses: Fungal Amyloid Is Bound by Host Serum Amyloid P Component. NPJ Biofilms Microbiomes (2015) 1. doi: 10.1038/npjbiofilms.2015.9

69. Moreira AP, Cavassani KA, Hullinger R, Rosada RS, Fong DJ, Murray L, et al. Serum Amyloid P Attenuates M2 Macrophage Activation and Protects Against Fungal Spore-Induced Allergic Airway Disease. J Allergy Clin Immunol (2010) 126(4):712-21 e7. doi: 10.1016/j.jaci.2010.06.010

70. Lu J, Marnell LL, Marjon KD, Mold C, Du Clos TW, Sun PD. Structural Recognition and Functional Activation of FcgammaR by Innate Pentraxins. Nature (2008) 456(7224):989-92. doi: 10.1038/nature07468

71. Pilling D, Gomer RH. Persistent Lung Inflammation and Fibrosis in Serum Amyloid P Component (APCs-/-) Knockout Mice. PloS One (2014) 9(4): e93730. doi: 10.1371/journal.pone.0093730

72. Cox N, Pilling D, Gomer RH. Serum Amyloid P: A Systemic Regulator of the Innate Immune Response. J Leukoc Biol (2014) 96(5):739-43. doi: 10.1189/ jlb.1MR0114-068R

73. Botto M, Hawkins PN, Bickerstaff MC, Herbert J, Bygrave AE, McBride A, et al. Amyloid Deposition Is Delayed in Mice With Targeted Deletion of the Serum Amyloid P Component Gene. Nat Med (1997) 3(8):855-9. doi: 10.1038/nm0897-855

74. Behrens NE, Lipke PN, Pilling D, Gomer RH, Klotz SA. Serum Amyloid P Component Binds Fungal Surface Amyloid and Decreases Human Macrophage Phagocytosis and Secretion of Inflammatory Cytokines. mBio (2019) 10(2). doi: 10.1128/mBio.00218-19

75. Raghu G, van den Blink B, Hamblin MJ, Brown AW, Golden JA, Ho LA, et al. Effect of Recombinant Human Pentraxin 2 vs Placebo on Change in Forced Vital Capacity in Patients With Idiopathic Pulmonary Fibrosis: A Randomized Clinical Trial. JAMA (2018) 319(22):2299-307. doi: 10.1001/ jama.2018.6129

76. Raghu G, van den Blink B, Hamblin MJ, Brown AW, Golden JA, Ho LA, et al. Long-Term Treatment With Recombinant Human Pentraxin 2 Protein in Patients With Idiopathic Pulmonary Fibrosis: An Open-Label Extension Study. Lancet Respir Med (2019) 7(8):657-64. doi: 10.1016/S2213-2600(19)30172-9

77. van den Blink B, Dillingh MR, Ginns LC, Morrison LD, Moerland M, Wijsenbeek M, et al. Recombinant Human Pentraxin-2 Therapy in Patients With Idiopathic Pulmonary Fibrosis: Safety, Pharmacokinetics and Exploratory Efficacy. Eur Respir J (2016) 47(3):889-97. doi: 10.1183/ 13993003.00850-2015

78. Gazendam RP, van de Geer A, Roos D, van den Berg TK, Kuijpers TW. How Neutrophils Kill Fungi. Immunol Rev (2016) 273(1):299-311. doi: 10.1111/ imr.12454

79. Rosbjerg A, Genster N, Pilely K, Skjoedt MO, Stahl GL, Garred P. Complementary Roles of the Classical and Lectin Complement Pathways in the Defense Against Aspergillus Fumigatus. Front Immunol (2016) 7:473. doi: 10.3389/fimmu.2016.00473

80. Ugurlar D, Howes SC, de Kreuk BJ, Koning RI, de Jong RN, Beurskens FJ, et al. Structures of C1-IgG1 Provide Insights Into How Danger Pattern Recognition Activates Complement. Science (2018) 359(6377):794-7. doi: 10.1126/science.aao4988

81. Lee MR, Huang HL, Chen LC, Yang HC, Ko JC, Cheng MH, et al. Seroprevalence of Aspergillus IgG and Disease Prevalence of Chronic Pulmonary Aspergillosis in a Country With Intermediate Burden of Tuberculosis: A Prospective Observational Study. Clin Microbiol Infect (2020) 26(8):1091.e1-7. doi: 10.1016/j.cmi.2019.12.009

82. Hosszu KK, Santiago-Schwarz F, Peerschke EI, Ghebrehiwet B. Evidence That a C1q/C1qR System Regulates Monocyte-Derived Dendritic Cell Differentiation at the Interface of Innate and Acquired Immunity. Innate Immun (2010) 16(2):115-27. doi: 10.1177/1753425909339815

83. Song Z, Cai L, Guo L, Tsukamoto Y, Yutani C, Li XA. Accumulation and Expression of Serum Amyloid P Component in Human Atherosclerotic Lesions. Atherosclerosis (2010) 211(1):90-5. doi: 10.1016/j.atherosclerosis. 2010.01.046

84. Pilling D, Roife D, Wang M, Ronkainen SD, Crawford JR, Travis EL, et al. Reduction of Bleomycin-Induced Pulmonary Fibrosis by Serum Amyloid P. J Immunol (2007) 179(6):4035-44. doi: 10.4049/jimmunol.179.6.4035 
85. Chai L, Netea MG, Teerenstra S, Earnest A, Vonk AG, Schlamm HT, et al. Early Proinflammatory Cytokines and C-Reactive Protein Trends as Predictors of Outcome in Invasive Aspergillosis. J Infect Dis (2010) 202 (9):1454-62. doi: 10.1086/656527

86. Roques M, Chretien ML, Favennec C, Lafon I, Ferrant E, Legouge C, et al. Evolution of Procalcitonin, C-Reactive Protein and Fibrinogen Levels in Neutropenic Leukaemia Patients With Invasive Pulmonary Aspergillosis or Mucormycosis. Mycoses (2016) 59(6):383-90. doi: 10.1111/myc.12487

87. Jensen TD, Schonheyder H, Andersen P, Stenderup A. Binding of C-Reactive Protein to Aspergillus Fumigatus Fractions. J Med Microbiol (1986) 21 (2):173-7. doi: 10.1099/00222615-21-2-173

88. Richardson MD, Gray CA, Shankland GS. Opsonic Effect of C-Reactive Protein on Phagocytosis and Intracellular Killing of Virulent and Attenuated Strains of Candida Albicans by Human Neutrophils. FEMS Microbiol Immunol (1991) 3(6):341-4. doi: 10.1111/j.1574-6968.1991. tb04259.x

89. Gaziano R, Bozza S, Bellocchio S, Perruccio K, Montagnoli C, Pitzurra L, et al. Anti-Aspergillus Fumigatus Efficacy of Pentraxin 3 Alone and in Combination With Antifungals. Antimicrob Agents Chemother (2004) 48 (11):4414-21. doi: 10.1128/AAC.48.11.4414-4421.2004

90. Lo Giudice P, Campo S, De Santis R, Salvatori G. Effect of PTX3 and Voriconazole Combination in a Rat Model of Invasive Pulmonary Aspergillosis. Antimicrob Agents Chemother (2012) 56(12):6400-2. doi: 10.1128/AAC.01000-12

91. Marra E, Sousa VL, Gaziano R, Pacello ML, Arseni B, Aurisicchio L, et al. Efficacy of PTX3 and Posaconazole Combination in a Rat Model of Invasive Pulmonary Aspergillosis. Antimicrob Agents Chemother (2014) 58(10):62846. doi: 10.1128/AAC.03038-14

92. Guegan H, Prat E, Robert-Gangneux F, Gangneux JP. Azole Resistance in Aspergillus Fumigatus: A Five-Year Follow Up Experience in a Tertiary Hospital With a Special Focus on Cystic Fibrosis. Front Cell Infect Microbiol (2020) 10:613774. doi: 10.3389/fcimb.2020.613774

93. Horvath A, Andersen I, Junker K, Lyck Fogh-Schultz B, Holm Nielsen E, Gizurarson S, et al. Serum Amyloid P Component Inhibits Influenza A Virus Infections: In Vitro and In Vivo Studies. Antiviral Res (2001) 52(1):43-53. doi: 10.1016/S0166-3542(01)00158-9
94. Pilling D, Gomer RH. The Development of Serum Amyloid P as a Possible Therapeutic. Front Immunol (2018) 9:2328. doi: 10.3389/fimmu.2018.02328

95. Nakagawa N, Barron L, Gomez IG, Johnson BG, Roach AM, Kameoka S, et al. Pentraxin-2 Suppresses C-Jun/AP-1 Signaling to Inhibit Progressive Fibrotic Disease. JCI Insight (2016) 1(20):e87446. doi: 10.1172/jci.insight.87446

96. Lahmer T, Kriescher S, Herner A, Rothe K, Spinner CD, Schneider J, et al. Invasive Pulmonary Aspergillosis in Critically Ill Patients With Severe COVID-19 Pneumonia: Results From the Prospective AspCOVID-19 Study. PloS One (2021) 16(3):e0238825. doi: 10.1371/journal.pone.0238825

97. Koehler P, Bassetti M, Chakrabarti A, Chen SCA, Colombo AL, Hoenigl M, et al. Defining and Managing COVID-19-Associated Pulmonary Aspergillosis: The 2020 ECMM/ISHAM Consensus Criteria for Research and Clinical Guidance. Lancet Infect Dis (2021) 21(6):e149-62. doi: 10.1016/S1473-3099(20)30847-1

Conflict of Interest: $\mathrm{AM}$ and $\mathrm{AD}$ are inventors of a patent on SAP (WO2020127471). AI is inventor of a patent on PTX3 (WO2006037744A1). $\mathrm{AM}, \mathrm{CG}$, and BB obtain royalties on reagents related to PTX3.

The remaining authors declare that the research was conducted in the absence of any commercial or financial relationships that could be construed as a potential conflict of interest.

Publisher's Note: All claims expressed in this article are solely those of the authors and do not necessarily represent those of their affiliated organizations, or those of the publisher, the editors and the reviewers. Any product that may be evaluated in this article, or claim that may be made by its manufacturer, is not guaranteed or endorsed by the publisher.

Copyright (c) 2021 Parente, Possetti, Erreni, D'Autilia, Bottazzi, Garlanda, Mantovani, Inforzato and Doni. This is an open-access article distributed under the terms of the Creative Commons Attribution License (CC BY). The use, distribution or reproduction in other forums is permitted, provided the original author(s) and the copyright owner(s) are credited and that the original publication in this journal is cited, in accordance with accepted academic practice. No use, distribution or reproduction is permitted which does not comply with these terms. 